\title{
Abdominal Panniculectomy Can Simplify Kidney Transplantation in Obese Patients
}

\author{
Dominik Promny $^{a} \quad$ Theresa Hauck $^{a} \quad$ Aijia Cai ${ }^{a} \quad$ Andreas Arkudas ${ }^{a}$ \\ Katharina Heller ${ }^{b, d}$ Bernd Wullich ${ }^{c, d}$ Hendrik Apel ${ }^{c, d}$ Raymund E. Horch ${ }^{a}$ \\ Ingo Ludolph ${ }^{\mathrm{a}}$
}

aDepartment of Plastic and Hand Surgery and Laboratory for Tissue Engineering and Regenerative Medicine, University Hospital Erlangen, Friedrich-Alexander-University Erlangen-Nürnberg (FAU), Erlangen, Germany; ${ }^{b}$ Department of Nephrology and Hypertension, University Hospital Erlangen, Friedrich-Alexander-University Erlangen-Nürnberg (FAU), Erlangen, Germany; ' Department of Urology and Pediatric Urology, University Hospital Erlangen, Friedrich-Alexander-University Erlangen-Nürnberg (FAU), Erlangen, Germany; ${ }^{\mathrm{d}}$ Transplant Center Erlangen-Nürnberg, University Hospital Erlangen, Friedrich-Alexander-University Erlangen-Nürnberg (FAU), Erlangen, Germany

\section{Keywords}

Kidney transplantation - Obesity · Panniculectomy ·

Perioperative complications · Transplantation

\begin{abstract}
Background: Obesity is frequently present in patients suffering from end-stage renal disease (ESRD). However, overweight kidney transplant candidates are a challenge for the transplant surgeon. Obese patients tend to develop a large abdominal panniculus after weight loss creating an area predisposed to wound-healing disorders. Due to concerns about graft survival and postoperative complications after kidney transplantation, obese patients are often refused in this selective patient cohort. The study aimed to analyze the effect of panniculectomies on postoperative complications and transplant candidacy in an interdisciplinary setting. Methods: A retrospective database review of 10 cases of ab-
\end{abstract}

dominal panniculectomies performed in patients with ESRD prior to kidney transplantation was conducted. Results: The median body mass index was $35.2 \mathrm{~kg} / \mathrm{m}^{2}$ (range 28.5-53.0 $\mathrm{kg} / \mathrm{m}^{2}$ ) at first transplant-assessment versus $31.0 \mathrm{~kg} / \mathrm{m}^{2}$ (range $28.0-34.4 \mathrm{~kg} / \mathrm{m}^{2}$ ) at panniculectomy, and $31.6 \mathrm{~kg} / \mathrm{m}^{2}$ (range $30.3-32.4 \mathrm{~kg} / \mathrm{m}^{2}$ ) at kidney transplantation. We observed no major postoperative complications following panniculectomy and minor wound-healing complications in 2 patients. All aside from 1 patient became active transplant candidates 6 weeks after panniculectomy. No posttransplant wound complications occurred in the transplanted patients. Conclusion: Abdominal panniculectomy is feasible in patients suffering ESRD with no major postoperative complications, thus converting previously ineligible patients into kidney transplant candidates. An interdisciplinary approach is advisable in this selective patient cohort.

(c) 2021 S. Karger AG, Basel karger@karger.com

(c) 2021 S. Karger AG, Basel

www.karger.com/uin
Correspondence to:

Ingo Ludolph, ingo.ludolph@uk-erlangen.de

\footnotetext{
Karger"
} 


\section{Introduction}

Over the past decades, the prevalence of obesity perpetually increased worldwide as did its associated health consequences [1]. Patients suffering from end-stage renal disease (ESRD) are increasingly affected by obesity $[2,3]$. Many studies have shown that a higher body mass index (BMI) $\left(\geq 30 \mathrm{~kg} / \mathrm{m}^{2}\right)$ is associated with chronic kidney disease as well as older age, diabetes mellitus, hypertension, and cardiovascular disease [4]. As renal disease progresses, the only way to end dependency on dialysis is a kidney transplantation. The kidney transplantation itself is the most common organ transplantation performed in the USA and Europe [5]. Thereby, the number of obese patients referred for evaluation for kidney transplantation increases [6]. Many transplant centers set up policies restricting transplantation among patients above a BMI threshold because there are concerns about the survival of the graft and the occurrence of severe postoperative complications [7].

To gain candidacy on the transplant waiting list, many of these patients lose weight. The massive weight loss results in abundant skin and the formation of an abdominal panniculus (Fig 1 and 2). For operations in the lower abdomen, especially in kidney transplantations, where adequate surgical access is impeded by excessive tissue, the abdominal panniculus might make the procedure challenging. Further, the subpannicular area is prone to increased moisture, skin maceration, recurrent eruptions, and elevated bacteria counts, predisposing this area to postoperative complications as wound infections and dehiscence [8]. The excess fatty tissue also increases the risk of a rupture of the abdominal wall fascia posttransplantation, causing subsequent reoperation and the use of a mesh, which makes access to the iliac vessels more difficult and extends the surgical and cold ischemia times for the transplanted organ. In general, the obese transplant recipient has an increased posttransplant risk of developing diabetes mellitus, poor blood pressure control, thromboembolism, and thus delayed convalescence time.

The highest priority for kidney transplantation surgeries is the proper function and survival of the organ. Therefore, an optimal presurgical preparation is mandatory. In addition to well-established arrangements prior to transplantation, the focus is also on accurate preparation of the surgical site. For obese patients, the goal is first to reduce weight and then perform additional abdominal pre-intervention with panniculectomy. Abdominal panniculectomy is an effective solution as it improves surgical access and reduces postoperative complications, and in patients

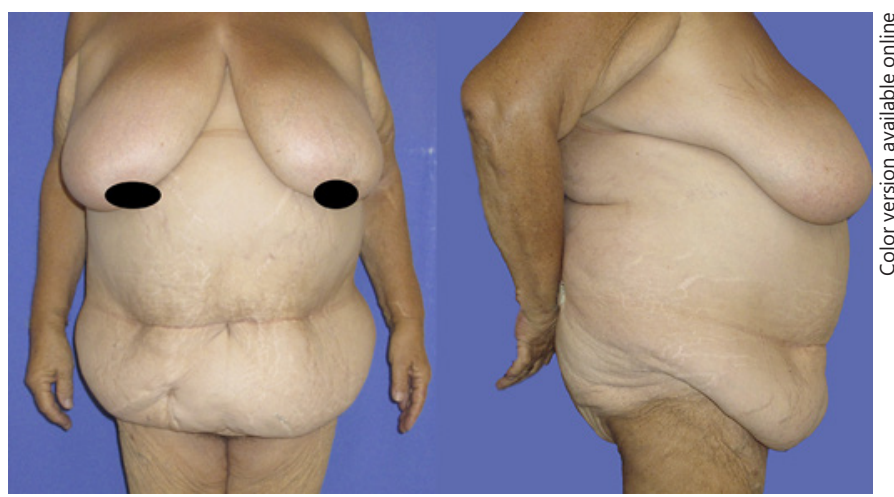

Fig. 1. Female patient after significant weight reduction resulting in abundant skin and the formation of an abdominal panniculus. The excessive tissue impedes the access to the surgical site. The subpannicular area is prone to moisture, skin maceration, and elevated bacteria count predisposing this area to postoperative complications.

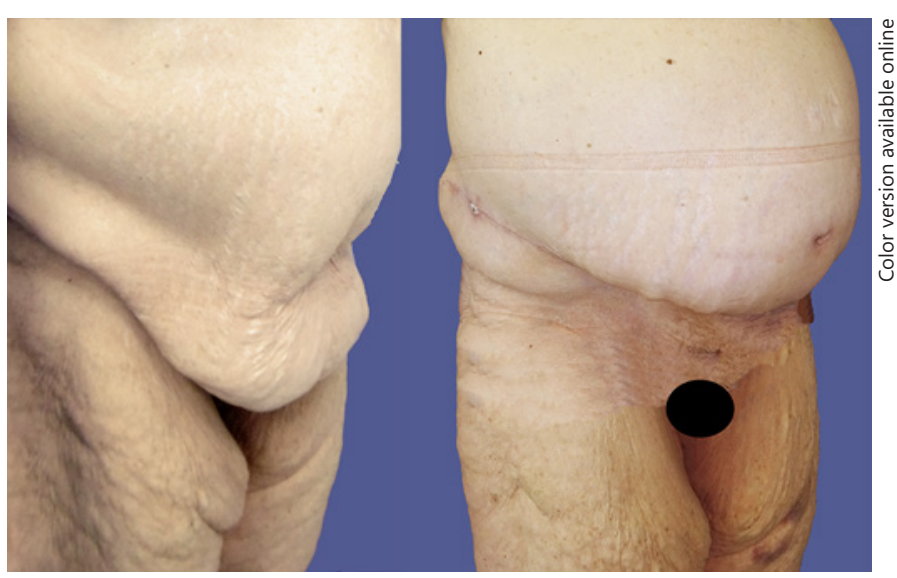

Fig. 2. Left: Female patient with an almost $60 \mathrm{~kg}$ weight reduction after lifestyle changes and bariatric surgery (sleeve gastrectomy) presenting with an abdominal panniculus. Right: 6 weeks after abdominal panniculectomy (resection weight 2,200 g).

suffering ESRD, it may convert previously ineligible patients into kidney transplant candidates [9-11]. This highly selective patient population is at a certain risk for postoperative surgical site infections and general complications because of malnutrition, renal anemia, inferior quality tissue, and often persistent obesity [12]. However, it has been shown that body-contouring surgery in patients with ESRD awaiting kidney transplantation can have an acceptable and manageable risk profile [13]. Nevertheless, there is scarce data available which analyzes 
Table 1. Indications and contraindications for panniculectomy

\begin{tabular}{ll}
\hline Indication & Contraindication \\
\hline Stable body weight $>6$ months & Multimorbid patient \\
Optimally adjusted secondary diagnosis & Active skin disease in surgical site \\
Stable hemoglobin value & Severe body weight fluctuations \\
BMI ideally $<35 \mathrm{~kg} / \mathrm{m}^{2}$ & Multiple previous abdominal surgeries/abdominal scars \\
Panniculus with low subcutaneous fat content & Extensive abdominal hernia (two-stage approach) \\
& Severe coagulation disorder \\
\hline
\end{tabular}

BMI, body mass index.

general feasibility, outcome, and postoperative complications of pretransplant abdominal panniculectomy [10, 14]. Therefore, we performed a single-center analysis of interdisciplinary treated patients suffering ESRD who underwent abdominal panniculectomy. We investigated minor and major postoperative complications after panniculectomy and the realization of postoperative listing of the patients on the transplant list.

\section{Materials and Methods}

We conducted a retrospective database review of ten cases of abdominal panniculectomies performed in patients with ESRD prior to kidney transplant between September 2016 and September 2020. All patients with ESRD who were referred to the institutional transplant board but had not been added to the transplant waiting list due to their abdominal panniculus were included. Table 1 presents the indications and contraindications for a panniculectomy before kidney transplantation.

The BMI calculation of enrolled patients was based on recorded weight prior to the abdominal panniculectomy. Additional data analyzed included sex, age (at the time of operation), surgery duration, resection weight, duration of hospitalization, comorbidities, history of abdominal surgery, and kidney function. Further, the occurrence of intra- and postoperative complications of panniculectomy was recorded. Surgical site complications were categorized according to the Clavien-Dindo classification [15].

Perioperative Management and Intraoperative Procedure

Following an interdisciplinary treatment approach, patients were categorized for abdominal panniculectomy by the institutional transplant board. All patients were advised to lose weight and present with a stable weight for a minimum of 6 months. There was no upper limit for BMI as an exclusion criterion for abdominal panniculectomy, whereas the decision to operate was based on the individual patient's related physical condition. Furthermore, prior to surgery, comorbidities such as hypertension, cardiovascular disease, diabetes, or coagulation disorders were assessed and optimized. In addition to routine clinical examinations, ultrasound and computed tomography scans were performed if necessary, in order to evaluate the abdomen for herniation. In the case of a de- tected abdominal hernia, simultaneous hernia repair was planned during the abdominal panniculectomy. A two-stage approach was chosen for abdominal panniculectomy and kidney transplantation.

To reduce panniculectomy-associated complications, unnecessary tissue mobilization was avoided. In addition to meticulous hemostasis following an intraoperatively induced blood pressure increase by the anesthesiologist, wound drainages were placed with removal once the output was less than $30 \mathrm{~mL}$ per $24 \mathrm{~h}$. Omphalectomy was performed at the least signs for mal-perfusion of the umbilicus to decrease the risk for reoperation or long-lasting wound-healing disorders. The surgical site was closed in a multilayer technique.

An abdominal compression garment was applied postoperatively and was worn for a period of 10 weeks postoperative. During the patients' hospital stay, thrombosis prophylaxis was performed. Standard perioperative antibiotic prophylaxis was given intravenously, with continuation for 7 days postoperatively.

As all patients were on a regular dialysis schedule, hemodialysis was organized 1 day before surgery and on the first postoperative day. Only in one case, due to a high postoperative potassium level, the dialysis had to be performed on the day of surgery.

Patients presented 6 weeks postoperative for follow-up visits at our outpatient clinic. Following a regular follow-up visit, patients were administered to our transplant center as soon as possible. The interdisciplinary team screened and reassessed the patients for listing for kidney transplantation.

\section{Statistics}

For data analysis, descriptive statistics were used. Demographic data were demonstrated as median and range. For statistical analysis, SPSS 24.0 for Windows was used (SPSS Inc., Chicago, IL, USA).

\section{Results}

Between 2016 and 2020, 10 patients (7 females, 3 males) underwent abdominal panniculectomies. The demographic data are shown in Table 2. The past medical history of all 10 patients is characterized by phases of severe obesity with a median BMI of $43.5 \mathrm{~kg} / \mathrm{m}^{2}$ (range 
Table 2. Baseline demographics at panniculectomy $(n=10)$

\begin{tabular}{lc}
\hline General & \\
Female, $n(\%)$ & $7(70)$ \\
Male, $n(\%)$ & $3(30)$ \\
Median age (range), year & $52(41-67)$ \\
Median BMI (range), kg/m ${ }^{2}$ & $31.0(28.0-34.4)$ \\
Diabetic, $n(\%)$ & $1(10)$ \\
Primary renal disease, $n(\%)$ & \\
Hypertensive nephropathy & $4(40)$ \\
Diabetic nephropathy & $1(10)$ \\
Focal-segmental glomerulosclerosis & $2(20)$ \\
Other & $3(30)$ \\
Dialysis, $n$ (\%) & $10(100)$ \\
Hemodialysis & $0(0)$ \\
Peritoneal dialysis & \\
Comorbidities at ESRD reporting, $n(\%)$ & $1(10)$ \\
Diabetes mellitus & $4(40)$ \\
Coronary artery disease & \\
Operation data & \\
Median panniculus weight (range), g & $2,400(2,000-3,000)$ \\
Median length of hospital stay & \\
$\quad$ (range), days & $8(6-26)$
\end{tabular}

BMI, body mass index; ESRD, end-stage renal disease.

$33.2-59.7 \mathrm{~kg} / \mathrm{m}^{2}$ ). At the time of panniculectomy, the median age was 52 years (range 41-67 years) with a median BMI of $31.0 \mathrm{~kg} / \mathrm{m}^{2}$ (range $28.0-34.4 \mathrm{~kg} / \mathrm{m}^{2}$ ). All patients were already on renal replacement treatment for several years, median 5.6 years (range 2.0-9.2 years), at the time of panniculectomy. The median panniculectomy resection weight was $2,400 \mathrm{~g}$ (range 2,000-3,000 g). The median postoperative hospitalization was 8 days (range 6-26 days). One of the patients developed an acute cholecystitis postoperatively and was referred to the abdominal surgery department for a cholecystectomy, extending the hospitalization to 26 days. Another patient with an artificial heart valve was admitted to the hospital 6 days before panniculectomy to adjust the anticoagulation. Three patients showed small hernias that were repaired simultaneously by using a surgical mesh. Furthermore, an omphalectomy was performed in these patients and in one additional patient due to a mal-perfusion. Considering possible anesthesia complications, we did not register any anesthesia-related adverse events.

None of the patients required operative reintervention for a panniculectomy complication. However, 1 patient experienced a complication Grade I Clavien-Dindo, presenting a small hematoma with a superficial infection, and 1 patient with Grade II complications showing a small wound dehiscence. Despite previous abdominal
Table 3. Current patient status after panniculectomy $(n=10)$

\begin{tabular}{ll}
\hline Current patient status & \\
\hline Transplanted, $n$ & 4 \\
Alive, functioning graft, $n(\%)$ & $4(100)$ \\
Alive, lost graft, $n(\%)$ & $0(0)$ \\
Deceased, $n(\%)$ & $0(0)$ \\
Not transplanted, $n$ & 6 \\
Registered on transplant waiting list, $n(\%)$ & $3(30)$ \\
Active status, $n$ & 3 \\
Inactive status, $n$ & 0 \\
In evaluation for transplantation, $n$ & 3 \\
Alive & 6 \\
Deceased & 0 \\
\hline
\end{tabular}

surgeries in 3 cases, we did not experience any complications when performing the panniculectomies.

\section{Current Patient Status}

Following an abdominal panniculectomy, all besides 1 patient became possible transplant candidates after 6 weeks. In this 1 case, the patient experienced a woundhealing disorder followed by secondary wound healing.

The median BMI at panniculectomy was $31.0 \mathrm{~kg} / \mathrm{m}^{2}$ (range $28.0-34.4 \mathrm{~kg} / \mathrm{m}^{2}$ ) with a median body weight of 83 $\mathrm{kg}$ (range $70-106 \mathrm{~kg}, 10$ patients) versus $31.6 \mathrm{~kg} / \mathrm{m}^{2}$ (range $30.3-32.4 \mathrm{~kg} / \mathrm{m}^{2}$ ) and a median body weight of $92 \mathrm{~kg}$ (range $78-105 \mathrm{~kg}, 4$ patients) at the day of transplantation. One of the transplanted patients gained $1.5 \mathrm{~kg}$ increasing the BMI to a higher level than before the panniculectomy. The others reduced their body weight or stayed at a steady state.

The median BMI was $35.2 \mathrm{~kg} / \mathrm{m}^{2}$ (range $28.5-53.0 \mathrm{~kg} /$ $\mathrm{m}^{2}$ ) on the first presentation of the patients at our transplant center. One patient showed a massive weight loss of more than $100 \mathrm{~kg}$. The median weight loss was $36.8 \mathrm{~kg}$ (range $20-116 \mathrm{~kg}$ ). In 1 patient bariatric surgery by means of a sleeve gastrectomy was performed in the past.

So far, 4 of these patients received a kidney transplant ( 2 from a living donor, 2 from a deceased donor) within 14.2 months (range 6.1-21.1 months) after their panniculectomy (see Tables 3,4). The median latency between dialysis and kidney transplantation was 7.1 years (range $5.8-11.5$ years).

In one case $(10 \%)$, the patient developed an arterial perfusion problem of the transplant which required immediate surgical revision. There was no graft loss in this case, nor in the other patients. Three months posttransplantation median eGFR (CKD EPI creatinine) was 48 $\mathrm{mL} / \mathrm{min}$ (range $36-56 \mathrm{~mL} / \mathrm{min}$ ). 
Table 4. Changes in patient's transplant listing before and after panniculectomy

\begin{tabular}{lllllll}
\hline Group & $\begin{array}{l}\text { ET - status at the } \\
\text { time of } \\
\text { panniculectomy }\end{array}$ & $N$ & $\begin{array}{l}\text { ET - status post } \\
\text { panniculectomy }\end{array}$ & $\begin{array}{l}\text { Time on dialysis to } \\
\text { panniculectomy median, } \\
\text { min-max, years }\end{array}$ & $\begin{array}{l}\text { Waiting time from } \\
\text { panniculectomy to "T"- } \\
\text { registration median, } \\
\text { min-max, months }\end{array}$ & $\begin{array}{l}\text { Waiting time from } \\
\text { panniculectomy to } \\
\text { transplantation median, } \\
\text { min-max, months }\end{array}$ \\
\hline 1 & Listed & 3 & $\mathrm{~T}$ & $7.50(7.22-9.19)$ & $7.08(4.30-10.62)$ & $21.11(21.11-21.11)$ \\
2 & Not listed & 4 & $\mathrm{~T}$ & $6.50(1.99-7.55)$ & $8.72\left(3.12-28.16^{*}\right)$ & $13.71(6.08-14.70)$ \\
3 & Not listed & 3 & None & $3.26(2.37-3.58)$ & n/a & n/a \\
\hline
\end{tabular}

ET, Eurotransplant; T, transplantable (patient on waiting list). Group 1 - Patients already listed on ET, several years before panniculectomy. Group 2 - Patients listed on ET-waiting list after panniculectomy. Group 3 - Patients not yet listed on ET, waiting list after panniculectomy. ${ }^{*}$ One patient only presented infrequently for listing evaluation, due to his foreign residency.

\section{Discussion}

One major factor impairing the access to a kidney transplantation is obesity. Obese patients often suffer comorbidities like hypertension, diabetes, arteriosclerosis, and musculoskeletal disorders. The development of bariatric surgery is a major step forward for otherwise therapy-resistant obesity [1].

In patients suffering from ESRD, the prevalence of obesity is higher compared to the general population [16]. Furthermore, dialysis patients represent a special, multimorbid patient population and are also affected by cardiovascular comorbidities, diabetes, chronic obstructive pulmonary disease, and cerebrovascular disease $[17,18]$. Those comorbidities are linked to intra- or postoperative complications. Hence, this specific group of patients represents a high-risk population for surgical intervention. Therefore, optimal interdisciplinary support before, during, and after an intervention is necessary to minimize those risks.

To reduce the surgery's risk during a kidney transplantation, a weight reduction is required in obese patients in the evaluation process [19-21]. Even if there is no exact definition of the ideal BMI for the surgical intervention of a kidney transplantation, different studies demonstrated that patients with a BMI of no higher than $26-28 \mathrm{~kg} /$ $\mathrm{m}^{2}$ show the best graft survival $[22,23]$.

However, extensive weight loss is considered one of the main factors for developing an abdominal panniculus [24]. An abdominal panniculus tends to cause complaints such as intertrigo, infections, sweating, skin irritation, and open wounds; which further increase the risk of developing postoperative complications. Potentially operations must then be carried out on immunosuppressed patients with a higher risk of graft loss $[25,26]$. However, panniculectomies have been performed successfully to improve gynecologic surgeries with good evidence for decreased wound complications [27]. We followed an analogous rationale to approach the abdominal panniculus in patients suffering from ESRD in need of a kidney transplantation.

Previous studies stated that body-contouring procedures showed a higher rate of complications in obese patients, with an increasing BMI being a risk factor for postoperative complications [28, 29]. Nonetheless, further studies demonstrated that body-contouring surgeries can be performed safely in patients with obesity [30,31].

Panniculectomy patients, even without renal disease, are prone to develop surgical site infections. Bailey et al. [10] stated that panniculectomies and abdominoplasties in patients with chronic kidney disease are linked to higher risk of complications than shown in the general population. Therefore, ideal preoperative conditions should be present to realize optimal results in obese patients undergoing abdominal panniculectomy as preparation for a kidney transplantation. A precise interdisciplinary patient selection with an accurate surgical preparation is mandatory. Further ways to minimize the risk of complication are the avoidance of tissue tension and unnecessary tissue mobilization, the sufficient amount and placement of drainages, the reduction of blood loss, and the resection of a mal-perfused umbilicus. With the goal of listing the patient for a kidney transplantation, the surgical team should prioritize function over cosmetics. Further, a two-stage approach is recommended. Primarily, the abdominal panniculectomy is performed, and subsequently, in a second surgery, the kidney transplantation is executed. Combining both procedures increases the risk of wound-healing disorders, due to poorly perfused fat tissue, certain tissue tension at the surgical site, 
risk of seroma, and a limited access to the situs for the transplant. Furthermore, with the initiation of immunosuppressive therapy after a successful transplantation, managing panniculectomy-related complications is challenging. This in turn increases the risk of graft loss. A two-stage approach avoids an extended operation time, a large panniculectomy incision, and a higher blood loss followed by the immediate initiation of the posttransplant immunosuppression [10,32]. There are studies available considering a simultaneous approach. However, Baglien et al. [33] describe a wound complication rate of $46.2 \%$ and a reoperation rate of $30.8 \%$ and Ngaage et al. [34] even depict a graft-related complication in almost $25 \%$.

Considering important technical aspects during the operation, the overall complication rate can be reduced to a minimum. In our study, we observed 1 patient with a localized late postoperative infection and 1 patient with a minor wound dehiscence. Neither of them needed surgical intervention. All patients improved with a wellhealed wound at the surgical site. Of the ten performed abdominal panniculectomies, $70 \%$ of the patients have been listed for kidney transplantation. Three cases are in evaluation for registration. None had their candidacy delayed due to complications from their abdominal panniculectomy.

In comparison to previously published studies on abdominal panniculectomy procedures in this high-selective patient population, our complication rate was found to be low. Bailey et al. [10] observed major wound-healing complications, which they defined as hematoma, seroma, and unplanned surgical intervention, in $14 \%$ of their patients. Minor complications (cellulitis or superficial wound separation) were recorded in $38 \%$ of the patients [10]. Mundra et al. [32] reported $10.6 \%$ of overall wound complications in their analyzed patient cohort. A possible explanation is, that nationwide inpatient samples only report on in-hospital complications, whereas most wound complications might be observed at the postoperative outpatient visits. To avoid this deficiency, the patients of our cohort are continuously presented to the interdisciplinary transplant center to react promptly to possible issues.

In the analysis of abdominoplasty in obese patients (BMI $>30 \mathrm{~kg} / \mathrm{m}^{2}$ ) different studies found major complications in up to $31.5 \%$ and minor complications of $53.4 \%$ [35]. However, the evaluation of complications should be critically compared due to inconsistent definitions of major and minor complications in the literature.
To evaluate the presence of an abdominal hernia, preoperative abdominal imaging should be performed [8]. In the case of a small abdominal hernia, the reconstruction can be performed in the same operation as the panniculectomy. However, in the case of a challenging large hernia, a separate, ideally laparoscopic, surgical intervention is advised [36].

The scar positioning of the panniculectomy should be determined in an interdisciplinary setting via consultation with the transplant surgeon to avoid complications at the site and to create ideal conditions for the following transplant surgery. From the transplant surgeon's point of view, a previous abdominal panniculectomy does not impede a kidney transplant because it does not restrict the options concerning to the choice and location of the transplant incision.

There are some limitations to this study that need to be discussed. First, there is an inherent selection bias, with the possibility that our study population does not reflect the ESRD patient population at large. A further limitation is the low number of patients, as we investigated a highly selective group of patients. In a prospective study design a comparison of panniculectomy patients with a similar patient population in BMI who did not undergo a panniculectomy before kidney transplantation would be of high interest.

Additionally, we cannot present any information about long-term graft survival. Nevertheless, we intended to show the feasibility of abdominal panniculectomy in obese patients suffering from ESRD and enable the patients' addition to the transplant waiting list.

\section{Conclusion}

With a raising number of patients suffering from ESRD and obesity simultaneously, there is a growing number of those patients listed for a kidney transplantation. Following weight loss before transplantation, the demand for panniculectomies might become an increasing problem in future.

This study shows the feasibility of safely performing an abdominal panniculectomy in the high-risk population of patients suffering from ESRD. Following an interdisciplinary two-staged surgical approach, complications can be reduced to a minimum. The pretransplant abdominal panniculectomy underlines the importance of an interdisciplinary setting to achieve best possible patient care in such a highly selective patient population. 


\section{Statement of Ethics}

This research complies with the guidelines for human studies and is in accordance with the World Medical Association Declaration of Helsinki. All enrolled patients gave written informed consent.

The paper is exempt from Ethical Committee approval. We present a retrospective study and the paper does not report on primary research. All data analyzed were collected as part of routine diagnosis and treatment. The paper does not report on the use of experimental or new protocols. Patients were diagnosed and treated according to common and accepted guidelines and agreements. Furthermore, data were only used anonymously. For the use of photographs, written informed consent was obtained by the patients.

\section{Conflict of Interest Statement}

The authors have no conflicts of interest to declare.

\section{Funding Sources}

The authors have no funding sources to declare.

\section{Author Contributions}

\begin{tabular}{llllll}
\hline Author name & $\begin{array}{l}\text { Study conception } \\
\text { and deign }\end{array}$ & $\begin{array}{l}\text { Acquisition } \\
\text { of data }\end{array}$ & $\begin{array}{l}\text { Analysis and } \\
\text { interpretation of data }\end{array}$ & $\begin{array}{l}\text { Drafting of } \\
\text { manuscript }\end{array}$ & $\begin{array}{l}\text { Critical revision } \\
\text { of manuscript }\end{array}$ \\
\hline Promny D. & $\times$ & $\times$ & $\times$ & $\times$ & $\times$ \\
Hauck T. & & $\times$ & $\times$ & & $\times$ \\
Cai A. & $\times$ & $\times$ & & $\times$ \\
Arkudas A. & $\times$ & $\times$ & $\times$ & $\times$ & $\times$ \\
Heller K. & $\times$ & $\times$ & & $\times$ \\
Wullich B. & $\times$ & $\times$ & & $\times$ \\
Apel H. & $\times$ & $\times$ & $\times$ & $\times$ \\
Horch R.E. & $\times$ & $\times$ & & $\times$ \\
Ludolph I. & $\times$ & $\times$ & $\times$ & & $\times$ \\
\hline
\end{tabular}

\section{References}

1 Collaborators GO, Afshin A, Forouzanfar MH, Reitsma MB, Sur P, Estep K, et al. Health effects of overweight and obesity in 195 countries over 25 years. N Engl J Med. 2017 Jul 6; 377(1):13.

2 Ladhani M, Craig JC, Irving M, Clayton PA, Wong G. Obesity and the risk of cardiovascular and all-cause mortality in chronic kidney disease: a systematic review and meta-analysis. Nephrol Dial Transplant. 2017 Mar 1; 32(3):439-49.

3 Whaley-Connell A, Sowers JR. Obesity and kidney disease: from population to basic science and the search for new therapeutic targets. Kidney Int. 2017 Aug;92(2):313-23.

42018 USRDS Annual Data Report. 2018; volume 1: CKD in the United States: 10

5 Weigand K. [Organ donation in Germany: don't we want to? can't we? or are we not allowed?] Urologe A. 2018 Sep;57(9):1091-9.

6 Ates D, Cebeci F. Obesity in the kidney transplant process. Exp Clin Transplant. 2018 Mar; 16(Suppl 1):61-3.

7 Lentine KL, Delos Santos R, Axelrod D, Schnitzler MA, Brennan DC, Tuttle-Newhall
JE. Obesity and kidney transplant candidates: how big is too big for transplantation? Am J Nephrol. 2012;36(6):575-86.

8 Hillenbrand A, Henne-Bruns D, Wolf AM. Panniculus, giant hernias and surgical problems in patients with morbid obesity. GMS Interdiscip Plast Reconstr Surg DGPW. 2012;1:Doc05.

9 Kuo JH, Troppmann C, Perez RV, Wong MS. Panniculectomy in preparation for renal transplantation: a new indication for an old procedure to reduce renal transplantationassociated wound complications. Plast Reconstr Surg. 2011 Dec;128(6):1236-40.

10 Bailey CM, Troppmann C, Kuo J, Wong MS. Panniculectomy in end-stage renal disease: six-year experience of performing panniculectomy in preparation for renal transplant. Ann Plast Surg. 2015 May;74(Suppl 1):S9-11.

11 Troppmann C, Santhanakrishnan C, Kuo JH, Bailey CM, Perez RV, Wong MS. Impact of panniculectomy on transplant candidacy of obese patients with chronic kidney disease declined for kidney transplantation because of a high-risk abdominal panniculus: a pilot study. Surgery. 2016 Jun;159(6):1612-22.
12 Pierpont YN, Dinh TP, Salas RE, Johnson EL, Wright TG, Robson MC, et al . Obesity and surgical wound healing: a current review. ISRN Obes. 2014;2014:638936.

13 Xue Y, Song P, Wong MS. Early experience with body contouring procedures in patients with end-stage renal disease awaiting renal transplant. Ann Plast Surg. 2019 May;82(5S Suppl 4):S339-41.

14 Dobrzycka M, Proczko-Stepaniak M, Kaska Ł, Wilczyński M, Dębska-Ślizień A, Kobiela J. Weight loss after bariatric surgery in morbidly obese end-stage kidney disease patients as preparation for kidney transplantation. Matched pair analysis in a high-volume bariatric and transplant center. Obes Surg. 2020 Jul;30(7):2708.

15 Dindo D, Demartines N, Clavien PA. Classification of surgical complications: a new proposal with evaluation in a cohort of $6336 \mathrm{pa}-$ tients and results of a survey. Ann Surg. 2004 Aug;240(2):205.

16 Lin TY, Liu JS, Hung SC. Obesity and risk of end-stage renal disease in patients with chronic kidney disease: a cohort study. Am J Clin Nutr. 2018 Nov 1;108(5):1145-53. 
17 Longenecker JC, Coresh J, Klag MJ, Levey AS, Martin AA, Fink NE, et al . Validation of comorbid conditions on the end-stage renal disease medical evidence report: the CHOICE study. Choices for healthy outcomes in caring for ESRD. J Am Soc Nephrol. 2000 Mar;11(3): 520-9.

18 Sarier M, Yayar O, Yavuz A, Turgut H, Kukul E. Update on the management of urological problems following kidney transplantation. Urologia internationalis. 2021 Jan 28.

19 Segev DL, Simpkins CE, Thompson RE, Locke JE, Warren DS, Montgomery RA. Obesity impacts access to kidney transplantation. J Am Soc Nephrol. 2008 Feb;19(2):349-55.

20 Huang E, Bunnapradist S. Pre-transplant weight loss and survival after kidney transplantation. Am J Nephrol. 2015;41(6):44855.

21 Ozturk SA, Yuksel Y, Erbis H, Aliosmanoglu I, Sarier M, Yayar O, et al . Laparoscopic live donor nephrectomy: experience of high-volume center with 2,477 cases. Urol Int. 2021; 105(1-2): 100 .

22 Lafranca JA, IJermans JN, Betjes MG, Dor FJ. Body mass index and outcome in renal transplant recipients: a systematic review and meta-analysis. BMC Med. 2015 May 12;13:111.

23 Li C, Jin H, Xiao L, Li Z, Cai M, Shi B. Association between overweight and renal transplant outcomes: a meta-analysis. Exp Clin Transplant. 2017 Oct;15(5):527-31.
24 Gallagher S, Gates JL. Obesity, panniculitis, panniculectomy, and wound care: understanding the challenges. J Wound Ostomy Continence Nurs. 2003 Nov;30(6):334-41.

25 Geierlehner A, Horch RE, Müller-Seubert W, Arkudas A, Ludolph I. Limb salvage procedure in immunocompromised patients with therapy-resistant leg ulcers-The value of ultra-radical debridement and instillation negative-pressure wound therapy. Int Wound J. 2020 Jun 22.

26 Horch RE, Ludolph I, Müller-Seubert W, Zetzmann K, Hauck T, Arkudas A, et al. Topical negative-pressure wound therapy: emerging devices and techniques. Expert Rev Med Devices. 2020 Feb;17(2):139-48.

27 Hopkins MP, Shriner AM, Parker MG, Scott L. Panniculectomy at the time of gynecologic surgery in morbidly obese patients. Am J Obstet Gynecol. 2000 Jun;182(6):1502-5.

28 Ghnnam W, Elrahawy A, Moghazy ME. The effect of body mass index on outcome of abdominoplasty operations. World J Plast Surg. 2016 Sep;5(3):244-51.

29 Renno I, Boos AM, Horch RE, Ludolph I. Changes of perfusion patterns of surgical wounds under application of closed incision negative pressure wound therapy in postbariatric patients1. Clin Hemorheol Microcirc. 2019;72(2):139-50
30 Mericli AF, Drake DB. Abdominal contouring in super obese patients: a single-surgeon review of 22 cases. Ann Plast Surg. 2011 May; 66(5):523-7.

31 Hauck T, Schmitz M, Horch RE, Arkudas A, Boos AM, Cai A, et al . Operating on the edge? body contouring procedures in patients with body mass index greater 35. Obes Surg. 2019 May;29(5):1563-70.

32 Mundra LS, Rubio GA, AlQattan HT, Thaller SR. Panniculectomy outcomes in patients with end-stage renal disease in preparation for renal transplant. Aesthetic Plast Surg. 2018 Jun;42(3):633-8.

33 Baglien B, Ngaage LM, Elegbede A, Gebran SG, Nam AJ, Niederhaus S, et al . Teamwork makes the dream work: maximizing surgical intervention at the time of living donor renal transplantation. Transplant Proc. 2020 Apr; 52(3):731.

34 Ngaage LM, Elegbede A, Tadisina KK, Gebran SG, Masters BM, Rada EM, et al . Panniculectomy at the time of living donor renal transplantation: An 8-year experience. Am J Transplant. 2019 Aug;19(8):2284.

35 Neaman KC, Hansen JE. Analysis of complications from abdominoplasty: a review of 206 cases at a university hospital. Ann Plast Surg. 2007 Mar;58(3):292-8.

36 Tsereteli Z, Pryor BA, Heniford BT, Park A, Voeller G, Ramshaw BJ. Laparoscopic ventral hernia repair (LVHR) in morbidly obese patients. Hernia. 2008 Jun;12(3):233-8. 